\title{
Trigger factor assisted self-assembly of canine parvovirus VP2 protein into virus- like particles in Escherichia coli with high immunogenicity
}

\author{
Liangliang Nan ${ }^{1,2+}$, Yunchao Liu ${ }^{2+}$, Pengchao $\mathrm{Ji}^{3+}$, Hua Feng ${ }^{2}$, Chen Chen ${ }^{1}$, Juan Wang ${ }^{4}$, Dongmin Liư ${ }^{4}$,
} Yinglei Cui ${ }^{2,3}$, Yanwei Wang ${ }^{2}$, Yafei $\mathrm{Li}^{1,2}$, Enmin Zhou ${ }^{1}$ and Gaiping Zhang ${ }^{1,2,3^{*}}$ [D

\begin{abstract}
Canine parvovirus (CPV) has been considered to be an important pathogen, which can cause acute infectious disease in canids. Although current vaccines are effective in preventing CPV infection, safety problems still remain unsolved. In this study, a subunit vaccine against CPV based on virus-like particles (VLPs) with good safety and immunogenicity is reported. Soluble CPV VP2 protein was produced by co-expression of chaperone trigger factor (Tf16) in Escherichia coli (E.coli), and assembled into CPV VLPs which could be affected by NaCl and pH. At $250 \mathrm{mM}$ $\mathrm{NaCl} \mathrm{pH} \mathrm{8.0,} \mathrm{the} \mathrm{VLPs} \mathrm{co-expressed} \mathrm{with} \mathrm{Tf16} \mathrm{had} \mathrm{similar} \mathrm{size}(25 \mathrm{~nm})$ and shape with the authentic virus capsid under the transmission electron microscopy (TEM), which is also in accordance with the dynamic light scattering (DLS) data. Immunization with these particles could induce high-titer hemagglutination inhibition (1:12288) and neutralizing antibodies (1:6144) in guinea pigs. Splenic cells of them could secrete IFN- $\gamma$ and IL-4 after stimulation by CPV. Thus, the VLPs produced by the new approach with high yield and immunogenicity could be a potential candidate for CPV vaccine.
\end{abstract}

Keywords: Canine parvovirus, Escherichia coli, Immunogenicity, Trigger factor 16, Virus-like particle

\section{Introduction}

Canine Parvovirus (CPV) disease is a highly contagious infectious disease caused by canine parvovirus, which is manifested as severe hemorrhagic enteritis in dogs of all ages and myocarditis in puppies [1]. Since it was first discovered in 1978, domestic dogs and some wild animals have been facing a huge risk because of the high morbidity and mortality throughout the world [2]. CPV belongs to genus Protoparvovirus within family Parvoviridae and has the ability to agglutinate pig erythrocytes [3]. It is a $25 \mathrm{~nm}$ diameter particle consisting of three structural proteins, VP1, VP2 and VP3. As the main component of viral capsid, VP2

\footnotetext{
*Correspondence: zhanggaiping2003@163.com

†Liangliang Nan, Yunchao Liu and Pengchao Ji contributed equally to this work.

${ }^{1}$ College of Veterinary Medicine, Northwest A\&F University, Yangling 712100, China

${ }^{2}$ Henan Provincial Key Laboratory of Animal Immunology, Henan Academy of Agricultural Sciences, Zhengzhou 450002, China

Full list of author information is available at the end of the article
}

protein can spontaneously assemble into VLPs and exhibit good immunogenicity [4].

CPV-2 was the original virus strain in dogs that spread worldwide, and soon gave rise to three antigenic variants with mutation sites in VP2 protein [5]. CPV-2a contained 5 amino acid substitutions (M87L, I101T, A300G, D305Y, and V555I) and is the predominant variant in Asia; CPV-2b had a single additional substitution (N426D) and an I555V reversion; CPV-2c featuring N426E and S297A is the predominant variant in Europe and Latin America [6-8].

Vaccination plays an important role in the prevention of this disease. Attenuated CPV-2 vaccines are effective and widely used, but large scale production of them is usually expensive and laborious. Although the attenuated CPV-2 vaccine strains are stable in limited passages in the dog, a series of CPV-2-like strains were identified and deduced to evolve from the vaccine strains [8]. Inactivated CPV vaccines are not recommended for routine use. They are less effective and take much longer to induce an immune

(C) The Author(s). 2018 Open Access This article is distributed under the terms of the Creative Commons Attribution 4.0 International License (http://creativecommons.org/licenses/by/4.0/), which permits unrestricted use, distribution, and 
response when compared with attenuated vaccines [9]. Thus, it is significant to develop alternative vaccines, such as virus-like particles (VLPs) based vaccine. VLPs are composed of viral structural proteins but lack viral genome. They could be recognized easily by the immune system and show dramatic effectiveness because of the present of viral antigens in a conformation like virus [10]. It was reported that CPV VLPs with good immunogenicity could be produced by the eukaryocyte system [4]. However, this method is complicated and costs a lot.

Prokaryotic expression system has been used extensively for recombinant proteins production in laboratory and industrial scale due to its simplicity, rapid growth rate and relatively low cost. Actually, it is not uncommon that overexpressed recombinant proteins fail to reach a correct conformation and are prone to associate with each other to form insoluble aggregates [11]. To cope with this situation, an increase in the intracellular concentration of molecular chaperones may be a useful strategy. Tigger factor (TF) is one of the most important molecular chaperones and the only prokaryotic chaperone associated with the ribosome [12]. It has a cleft-like concave binding pocket for potential substrates to assist proper folding of them in the crowded cellular environment [13]. Co-expression of TF has successfully enhanced yield and biological activity of some recombinant proteins in Escherichia coli (E.coli), such as bovine carbonic anhydrase II [14].

In this study, we obtained high-yield soluble VP2 protein by co-expression with chaperone Tf16 in E.coli. Under the optimum condition ( $250 \mathrm{mM} \mathrm{NaCl} \mathrm{pH} \mathrm{8.0),} \mathrm{the} \mathrm{VLPs} \mathrm{as-}$ sembled by the VP2 protein were used to immunize guinea pigs. The immunological tests suggested that this kind of VLPs has high immunogenicity and may be a promising candidate vaccine against $\mathrm{CPV}$.

\section{Materials and methods}

\section{Cells and virus}

Feline kidney F81 cells were cultured in Dulbecco's modified Eagle's medium (DMEM; Hyclone), which was supplemented with $100 \mathrm{U} / \mathrm{ml}$ of penicillin, $100 \mathrm{mg} / \mathrm{ml} \mathrm{of}$ streptomycin and 10\% fetal bovine serum (FBS; Gibco) at $37^{\circ} \mathrm{C}$ in a $5 \% \mathrm{CO}_{2}$ incubator.

The virus was isolated from feces of an infected puppy as described previously [15]. DNA was extracted from the infected F81 cells by TIANamp Virus DNA/RNA Kit (Takara, China). The VP2 gene was amplified by PCR and sequenced (Sangon, China). To examine the titration, F81 cells were seeded into 96-well plates. At 60\% confluency, cells were overlaid with serially 10 -fold diluted supernatant of CPV-infected cells for $1 \mathrm{~h}$ at $37^{\circ} \mathrm{C}$. Then the supernatant was changed to medium supplemented with $3 \%$ FBS. After $72 \mathrm{~h}$ incubation at $37{ }^{\circ} \mathrm{C}$, the cytopathic effect (CPE) was assessed by immunoperoxidase monolayer assay (IPMA).
The CPV was used for all the immunological tests in this study.

\section{Plasmid construction and expression}

The sequence of VP2 protein was optimized based on CC8601 strain (GenBank accession number GU569948). The complete VP2 gene was amplified by a pair of primers (Songon, China). The forward primer was 5'-GAGGAT CC (BamHI) ATGAGCGATGGTGCAGT-3', and the reverse primer was 5'-GATCTCGAG (XhoI) TTAGTACAG TTTGCGCGG-3'. The VP2 gene was digested by the restriction endonucleases $\mathrm{BamHI}$ and $\mathrm{XhoI}$, and sub-cloned into pET30a (pET30a-VP2). Then the recombinant plasmid was transformed into $E$. coli BL21 (DE3) competent cells harboring pTf16, which were prepared according to the manufacturer's protocol (TaKaRa, China).

The colony, positive for both VP2 protein and Tf16, were cultured into LB medium containing $2 \mathrm{mg} / \mathrm{ml} \mathrm{L-Ar-}$ abinose, $0.1 \mathrm{mM}$ IPTG, $0.1 \mathrm{mg} / \mathrm{ml}$ chloramphenicol and kanamycin. After $14 \mathrm{~h}$ induction at $25{ }^{\circ} \mathrm{C}$, the cells were harvested and lysed by sonication in buffer A (400 mM $\mathrm{NaCl}, 50 \mathrm{mM}$ Tris, $\mathrm{pH}$ 8.0) on ice. The supernatant and debris were collected by centrifugation at $10000 \mathrm{~g}$ for $20 \mathrm{~min}$ and analyzed by SDS-PAGE.

\section{Purification of CPV VP2 protein}

The VP2 protein with an N-terminal His tag was purified by Ni-NTA affinity chromatography (Merck, Germany). Briefly, the clarified supernatant was loaded on the Ni-NTA column at a flow rate of $1 \mathrm{ml} / \mathrm{min}$ for 3 times. The column was washed with buffer B (400 mM NaCl, $50 \mathrm{mM}$ Tris, $30 \mathrm{mM}$ imidazole, $\mathrm{pH}$ 8.0) until no protein was detected by CBB staining (TIANGEN, China). The recombinant VP2 protein was thoroughly eluted with buffer C (400 mM $\mathrm{NaCl}, 50 \mathrm{mM}$ Tris, $150 \mathrm{mM}$ imidazole, $\mathrm{pH}$ 8.0) and analyzed by SDS-PAGE and Western blot.

\section{VLPs assembly condition and characterization}

The eluted VP2 protein was dialyzed against $50 \mathrm{mM}$ Tris with different concentrations of $\mathrm{NaCl}(150 \mathrm{mM}, 250 \mathrm{mM}$, $400 \mathrm{mM}$ ) and $\mathrm{pH}(\mathrm{pH} 7.0, \mathrm{pH} 8.0)$ at $4{ }^{\circ} \mathrm{C}$ for $16 \mathrm{~h}$. To analyze the assembly condition and appearances of VLPs, the collected protein was detected by dynamic light scattering (DLS) and transmission electron microscopy (TEM).

\section{Guinea pigs immunization with CPV VLPs}

Thirty female guinea pigs housed under pathogen-free conditions were randomly divided into five groups $(n=5)$. Group A, B and C were intramuscularly immunized with $10 \mu \mathrm{g}, 30 \mu \mathrm{g}$ and $50 \mu \mathrm{g}$ CPV VLPs mixed with Montanide ${ }^{\mathrm{TM}}$ ISA 201 VG (Seppic, France), respectively; group D was inoculated with $100 \mu \mathrm{l}$ commercial live-attenuated vaccine as a positive control; group E was injected with $100 \mu \mathrm{l}$ PBS as a negative control. Booster immunization with the same 
doses of VLPs was performed at 21 dpi (days post inoculation). Blood samples were collected from the forelimb veil at $0,14,21,28,35$ and $42 \mathrm{dpi}$.

\section{Anti-CPV antibody detection}

All serum samples from guinea pigs were inactivated at $56^{\circ}$ $\mathrm{C}$ for $30 \mathrm{~min}$ and diluted in a two-fold series starting at 1:30. After incubation with $100 \mathrm{TCID}_{50}$ of CPV at $37^{\circ} \mathrm{C}$ for $2 \mathrm{~h}$, the virus/serum mixtures were added to 96-well plates containing F81 cells at $37{ }^{\circ} \mathrm{C}$ and $5 \% \mathrm{CO}_{2}$. After three days, the cytopathic effect (CPE) was assessed by immunoperoxidase monolayer assay (IPMA). The highest dilution of sera showing complete inhibition of $\mathrm{CPE}$ was taken as the neutralization titer.

Hemagglutination inhibition (HI) assay was performed as described previously [3]. Briefly, serially diluted serum samples were mixed with 4 hemagglutination (HA) units of virus antigen. The mixtures were then incubated with freshly prepared $0.8 \%$ pig erythrocytes in 96-well V-shaped microtiter plates. HI antibody titers were expressed as the reciprocal of the final dilution of serum which completely inhibited hemagglutination.

\section{Analysis of cytokine production}

Spleens of guinea pigs from each group were removed under sterile conditions at $42 \mathrm{dpi}$. Cells were washed twice with RPMI 1640 containing 10\% FBS and filtered by Cell Strainers (Falcon, USA). Red blood cells (RBCs) in the cell suspension were lysed using RBC lysis buffer (20 mM Tris, $160 \mathrm{mM} \mathrm{NH}_{4} \mathrm{Cl}, \mathrm{pH} \mathrm{7.4)}$ for $6 \mathrm{~min}$ at room temperature. Then spleen lymphocytes were seeded in 96-well plates and stimulated by CPV. After 48 h' incubation at $37{ }^{\circ} \mathrm{C}$, cell culture supernatants were tested using commercial IL-4 and IFN- $\gamma$ ELISA kits (Bogoo, China) according to the manufacturer's instructions.

\section{Statistical analyses}

All values were tested for significance by one-way analysis of variance (ANOVA) using GraphPad Prism version 5.00 (GraphPad Software, San Diego, CA, USA). The significance level was set at $0.05(p<0.05)$.

\section{Results}

\section{Expression and purification of VP2 protein}

The soluble VP2 protein was expressed by co-transformation with pTf16 and confirmed through SDS-PAGE and Western blot. The result showed that a $70 \mathrm{kDa}$ protein was produced corresponding to the predicted molecular weight of His-VP2 protein (Fig. 1a). The yield of soluble VP2 protein was improved after co-expression with Tf16 (56 kDa), and the purity of it could be about $90 \%$ after purification by Ni-NTA affinity chromatography (Fig. 1b). Western blot analysis further confirmed that the purified
$70 \mathrm{kDa}$ protein is the target protein by using an anti-CPV polyclonal antibody (Five Star, China) (Fig. 1c).

\section{Assembly condition and characterization of VLPs}

To understand the effect of $\mathrm{pH}$ and $\mathrm{NaCl}$ on the assembly of CPV VLPs, the purified protein were analyzed by DLS. As demonstrated in Fig. 2a, there are more VLPs with same size as CPV $(25 \mathrm{~nm})$ at $\mathrm{pH} 8.0$ than that at $\mathrm{pH}$ 7.0. Thus, the optimal salt concentration was further analyzed at $\mathrm{pH}$ 8.0. DLS data showed that the size of recombinant VLPs changed within a narrow range and became larger as the increase of $\mathrm{NaCl}$ concentration. The highest amount of particles, with a dimension of approximately $25 \mathrm{~nm}$, was obtained at $250 \mathrm{mM} \mathrm{NaCl}$ pH 8.0 (Fig. 2b). They also have similar shape with the authentic virus capsid under TEM (Fig. 2c). However, relatively small particles $(14.80 \mathrm{~nm})$ were formed without co-expression of molecular chaperone Tf16 and showed unclear edges under TEM (Fig. 2d and e).

\section{Genotyping of isolated CPV}

DNA sequencing was performed for the amplified CPV VP2 gene. Nucleotide sequence comparisons to current $\mathrm{CPV}$ revealed that the virus belongs to CPV-2a strain and shares 100\% VP2 identity with strain SD-14-5 (GenBank accession number KR611515).

\section{Antibody response in guinea pigs}

To test whether CPV VLPs could induce specific humoral immune responses, guinea pigs were divided into five groups and immunized with different doses of CPV VLPs $(10 \mu \mathrm{g}, 30 \mu \mathrm{g}, 50 \mu \mathrm{g}), 100 \mu \mathrm{l}$ commercial CPV vaccine and PBS. As shown in Fig. 3a, neutralizing antibody titers of $50 \mu \mathrm{g}$ group increased dramatically and then reached to the highest (1:6144) at 35 dpi. Meanwhile, high-titer HI antibodies were also induced strongly in $50 \mu \mathrm{g}$ group and peaked (1:12288) at $35 \mathrm{dpi}$ (Fig. 3b). The humoral immune responses of VLPs groups changed in a dose-dependent manner and shared similarities in the growth trend. The antibody titers of them were consistently significantly higher $(p<0.05)$ than PBS group after the second immunization.

\section{Assays of cytokines}

IFN- $\gamma$ and IL-4 from the splenocytes of guinea pigs were detected by ELISA. As Fig. 4a shown, the amount of IFN- $\gamma$ was significantly higher in $10 \mu \mathrm{g}(p<0.001)$ and $30 \mu \mathrm{g}(p<$ $0.05)$ immunized groups than the control group. No significant difference was found between the commercial CPV vaccine and PBS group. The IL-4 content of VLPs vaccinated groups changed in a dose-dependent manner. The VLPs and commercial vaccine groups showed significantly higher $(p<0.01)$ IL-4 production compared to the control group (Fig. 4b). 


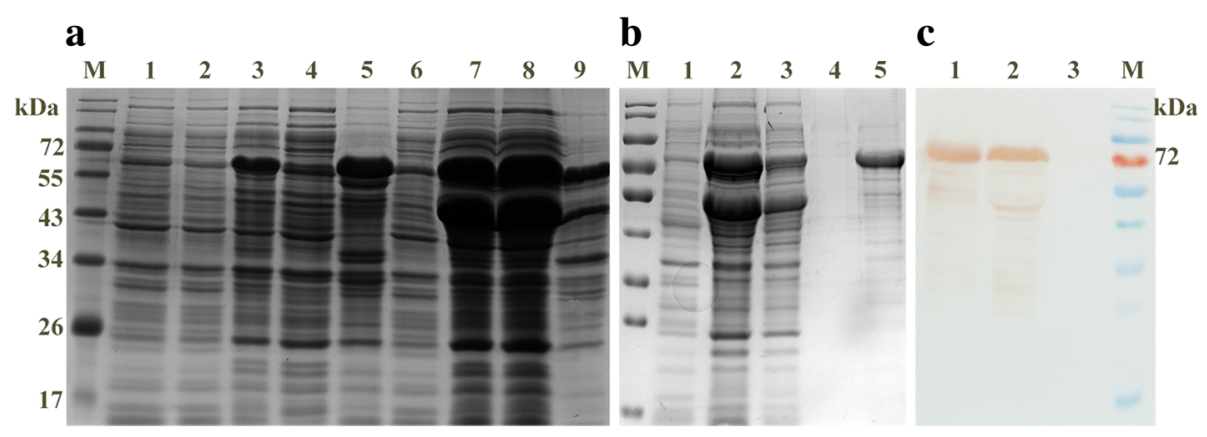

Fig. 1 Expression and purification of CPV VP2 protein co-expressed with Tf16. CPV VP2 protein were analyzed by 12\% SDS-PAGE and Western blot using an anti-CPV polyclonal antibody a SDS-PAGE analysis of the VP2 protein expression. Lane M, protein molecular weight (MW) markers; Lane 1, pET30a vector control; Lane 2, pET30a-VP2 cells before induction of IPTG; Lane 3, induced pET30a-VP2 cells; Lane 4, induced pET30a-VP2 cell lysate; Lane 5, inclusion body of induced pET30a-VP2 cells; Lane 6, pET30a-VP2-Tf16 cells before induction of IPTG and LArabinose; Lane 7, induced pET30a-VP2-Tf16 cells; Lane 8, induced pET30a-VP2-Tf16 cell lysate; Lane 9, inclusion body of induced pET30aVP2-Tf16 cells. b SDS-PAGE analysis of purification of VP2 protein co-expressed with chaperone Tf16. Lane 1, cells before induction; Lane 2, induced cells lysate; Lane 3, flow buffer; Lane 4, wash buffer; Lane 5, purified VP2 protein. c Western-blot analysis of purified VP2 protein with an anti-CPV polyclonal antibody. Lane1, purified VP2 protein; Lane 2, induced cell lysate; Lane 3, cells before induction. The MW of VP2 protein is approximately $70 \mathrm{kDa}$. The Tf16 is approximately $56 \mathrm{kDa}$

The stimulated $\mathrm{T}$ lymphocytes produced a much higher concentration of IFN- $\gamma$ compared to IL-4 in both the $10 \mu \mathrm{g}$ and $30 \mu \mathrm{g}$ VLPs groups, but the situation was opposite in the commercial vaccine group. As shown in Fig. $4 \mathrm{~b}$, the mean amount of IL-4 secreted in the guinea pigs vaccinated with $10 \mu \mathrm{g}$ and $30 \mu \mathrm{g}$ of the VLPs was about 42 and $60 \mathrm{pg} /$ $\mathrm{ml}$, respectively. And the mean amount of IFN- $\gamma$ secreted in the same groups was about 202 and $120 \mathrm{pg} / \mathrm{ml}$ (Fig. 4a). However, $64 \mathrm{pg} / \mathrm{ml} \mathrm{IL}-4$ and $9 \mathrm{pg} / \mathrm{ml} \mathrm{IFN- \gamma}$ were secreted in the commercial vaccine group (Fig. 4a and b).

\section{Discussion}

The most important enteric virus infecting canids is CPV. Although injection of attenuated vaccine is an effective way to control this disease currently, it may bring some safety concerns for immunized dogs [9]. The need for developing alternative vaccines, such as VLP-based vaccine, would be very urgent. It mimics virus particles, presenting considerable antigenic epitopes which can stimulate a diverse set of immune responses [16]. In this study, we produced CPV VLPs by co-expression with Tf16 in E.coli.
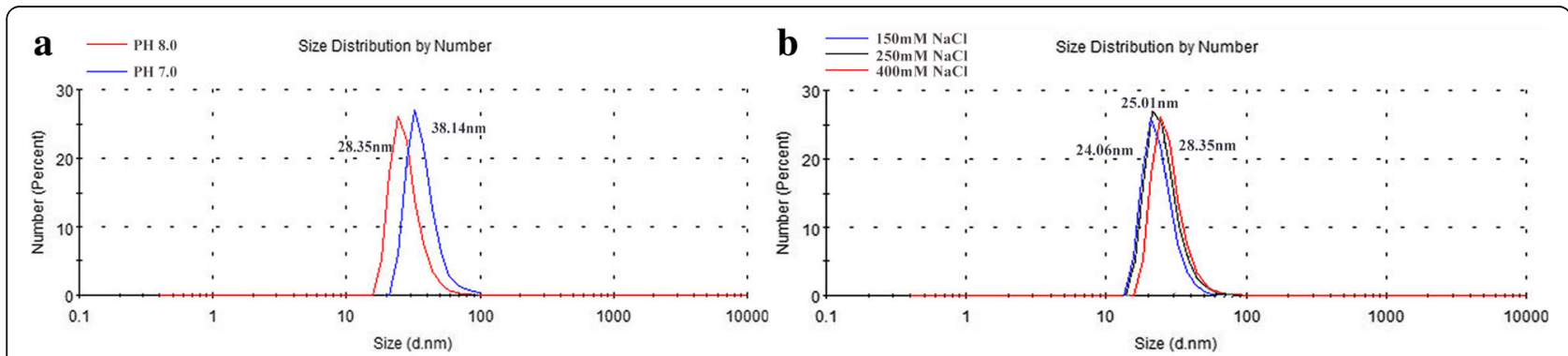

c

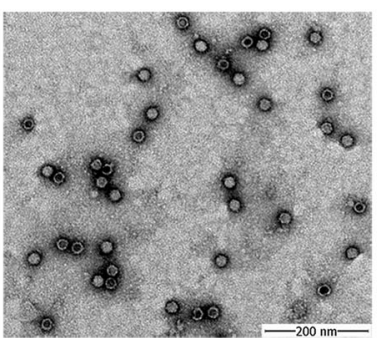

d

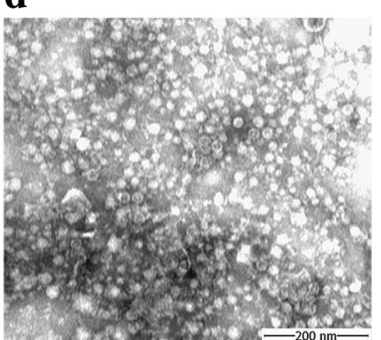

e

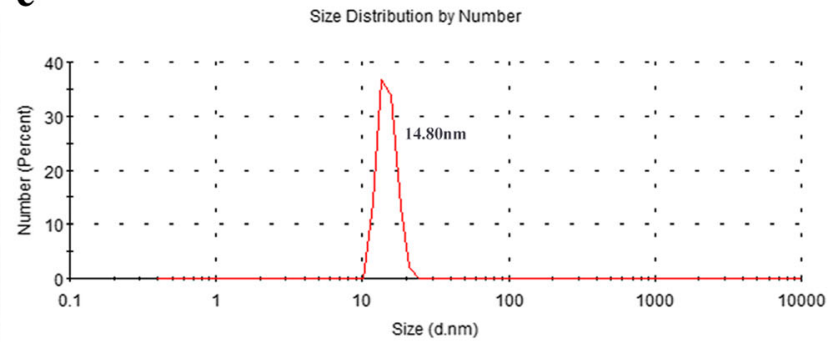

Fig. 2 Assembly and characterization of CPV VLPs under different conditions. a DLS results of VLPs assembled at pH 7.0 and 8.0. b DLS results of VLPs assembled in different concentrations of $\mathrm{NaCl}(150,250,400 \mathrm{mM})$. c TEM result of VLPs co-expressed with Tf16. Bar $=200$ $\mathrm{nm} \mathbf{d}$ TEM result of VLPs without co-expression of Tf16. Bar $=200 \mathrm{~nm}$ e DLS result of VLPs without co-expression of Tf16 

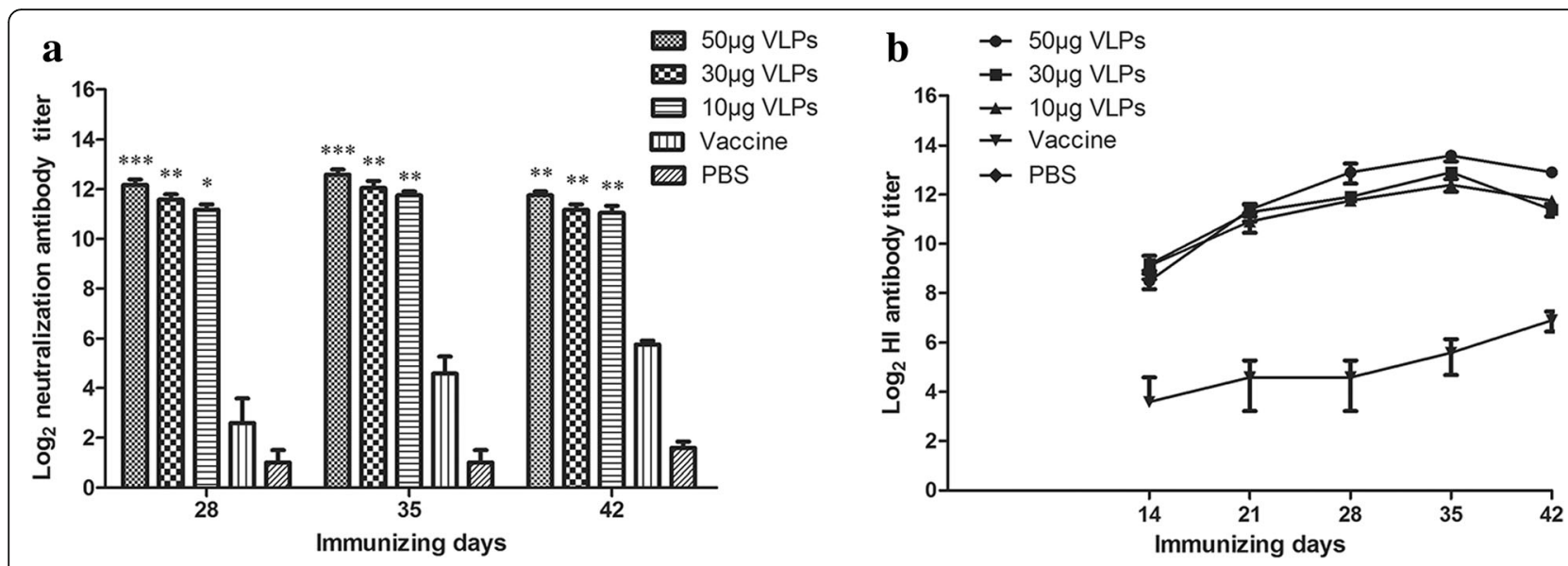

Fig. 3 Anti-CPV antibody responses in guinea pigs. Groups of guinea pigs $(n=5)$ were immunized with $50 \mu g, 30 \mu g$ and $10 \mu g$ of CPV VLPS, commercial CPV vaccine and PBS. Serum samples were collected once a week until $42 \mathrm{dpi}$ for the detection of neutralization and $\mathrm{HI}$ antibody titers. a Neutralization antibody titers of guinea pigs. b HI antibody titers of guinea pigs. The values are expressed as means \pm SEM. The statistical significance of antibody titer differences between vaccinated and PBS control guinea pigs were analyzed by one-way ANOVA statistical analysis $\left({ }^{*} p<0.05,{ }^{* *} p<0.01\right.$, and $\left.{ }^{* *} p<0.001\right)$

These particles could induce strong immune responses in guinea pigs.

It has been predicted that VP2 protein with high molecular weight and weak hydrophilicity, is more prone to accumulate as inclusion bodies in E.coli [17]. Some methods failed to achieve in VP2 soluble expression $[18,19]$ and correct refolding of the protein. In this study, the proportion of the VP2 protein in supernatant increased after the involvement of Tf16. One reason for its high solubility may be that Tf16 has the ability to prevent VP2 nascent chains from misfolding and aggregation after being translated by the ribosome $[20,21]$. This is a quick and easy method for producing high yield protein, because we can also remove Tf16 conveniently from the supernatant (Fig. 1b). A previous study reported that high yield soluble VP2 protein could be successfully produced with small ubiquitin-like modifier (SUMO) fusion motif in E.coli [17], but the SUMO-VP2 protein needs cleavage and re-purification, which may affect the yield of mass production.

The stability of viral protein and the formation process of VLPs are susceptible to salt concentration and $\mathrm{pH}$ [22]. These effects could be detected by DLS and TEM, which are the common approaches for VLPs size measurement and could verify the assembled condition of particles [23]. In the current study, pH-induced assembly of CPV VLPs was observed by DLS, which is similar with a previous study about human parvovirus B19 VLPs [24]. The effect indicated the involvement of ionizable groups at the interfaces between CPV capsid proteins. In addition, salt can stabilize protein by influencing ionic interaction on its
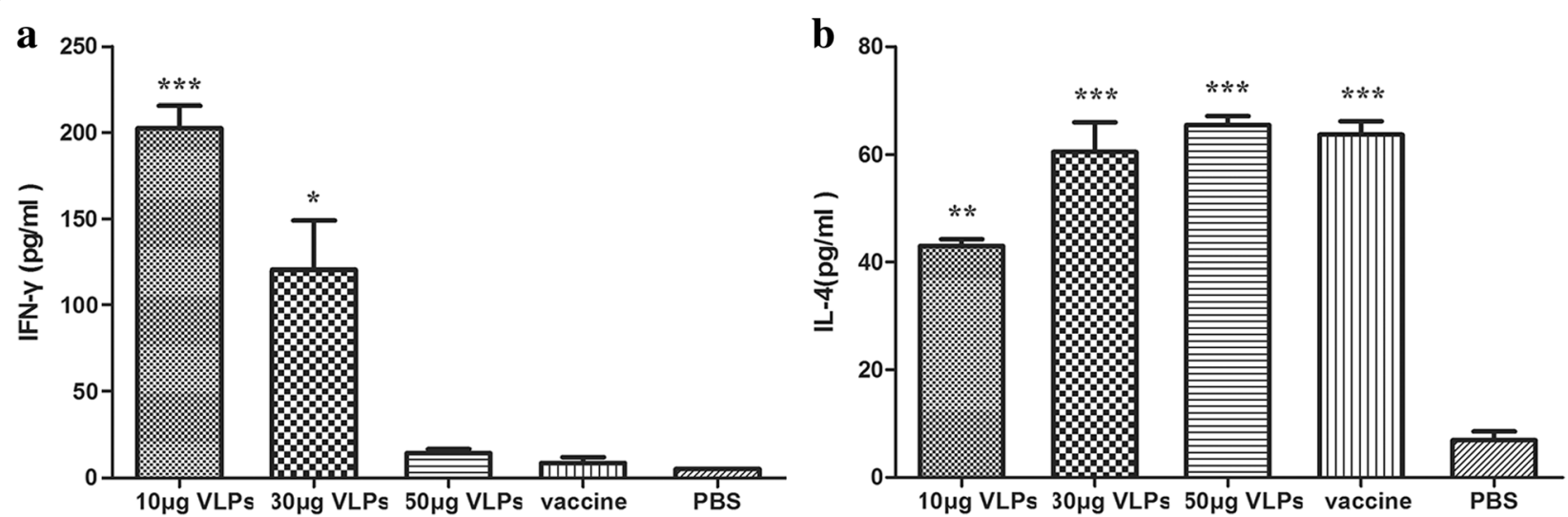

Fig. 4 Analysis of cytokine production secreted from the spleen lymphocytes of guinea pigs. Spleens of guinea pigs from each group were removed at $42 \mathrm{dpi}$. The culture supernatants of cells stimulated by CPV were collected after $72 \mathrm{~h}$ and detected by ELISA kits. a the concentration of guinea pig IFN- $\gamma$ in each group. $\mathbf{b}$ the concentration of guinea pig IL-4 in each group. The values are expressed as means \pm SEM. The statistical significance of cytokine concentration differences between vaccinated and PBS control guinea pigs were analyzed by one-way ANOVA statistical analysis $\left({ }^{*} p<0.05,{ }^{* *} p<0.01\right.$, and $\left.{ }^{* * *} p<0.001\right)$ 
surface [25], so we added different concentration of $\mathrm{NaCl}$ in the buffer. At pH 8.0, the size of VLPs changed within a narrow range as the increase of $\mathrm{NaCl}$ concentration. This suggested that ionic strength $(150-400 \mathrm{mM} \mathrm{NaCl})$ may make less difference to VLPs assembly in our study. Although the CPV VLPs assembled efficiency was unknown, it was estimated that the VLPs could be formed with similar size and shape as $\mathrm{CPV}$ at $250 \mathrm{mM} \mathrm{NaCl} \mathrm{pH} \mathrm{8.0.} \mathrm{Inter-}$ estingly, a relatively small particle $(14.80 \mathrm{~nm})$ was formed without Tf16 co-expression and showed unclear edges under TEM, which may result from the incorrect folding and insufficient amount of VP2 protein.

To evaluate the immunogenicity of CPV VLPs, anti-CPV antibodies were tested in the immunized guinea pigs. In VLPs immunized groups, HI antibody titers increased rapidly after the second immunization may because of the stimulated memory B cells. It is remarkable that the maximum titers of $\mathrm{HI}$ antibody and neutralization antibody were 1:12288 and 1:6144 respectively at $35 \mathrm{dpi}$ in $50 \mu \mathrm{g}$ VLPs group. A powerful response was also observed in $10 \mu \mathrm{g}$ group, despite the lower immune dose compared to the previous study $[17,26]$. It indicated that the antibodies could easily bind to antigens on the surface of CPV to prevent entering cells and agglutinating pig erythrocytes. Such good immunogenicity suggested that the VP2 protein expressed in E. coli could be fold correctly with natural bioactivity. Strong humoral immune responses may also result from the appropriate adjuvant (Montanide ${ }^{\text {tw }}$ ISA 201 VG) which is robust, stable, with low viscosity and easy to inject, compared to traditional oil emulsions. In addition, the low level of $\mathrm{HI}$ antibodies (1:192) and neutralization antibodies (1:60) induced by the commercial CPV vaccine may be related to the absence of a host animal. Here, we just regard the commercial vaccine as a positive control and a challenge test will be performed in dogs to evaluate the immune protection in the future.

It has been well documented by previous studies that CPV VLPs could induce proliferation of $\mathrm{CD}^{+}$and $\mathrm{CD} 8^{+} \mathrm{T}$ cells in mice $[17,26]$. Furthermore, T-helper type 1 (Th1) and T-helper type2 (Th2) cells are two subsets of $\mathrm{CD} 4^{+} \mathrm{T}$ cells which related to cellular and humoral adaptive immunity, respectively [27]. In this study, IFN- $\gamma$ (Th1-type cytokine) and IL-4 (Th2-type cytokine) were measured after CPV stimulation to evaluate the Th1 and Th2 responses. In the $10 \mu \mathrm{g}$ and $30 \mu \mathrm{g}$ VLPs groups, stimulated $\mathrm{T}$ lymphocytes produced a much higher concentration of IFN- $\gamma$ compared to IL-4, but in the commercial vaccine group, the situation was opposite. The results indicated that the VLPs may mainly stimulate Th1 response compared with the commercial vaccine in guinea pigs. The strong Th1 type-specific immune response attained partly by interaction of VLPs with DCs can also be induced by several other kinds of VLP-based vaccines, such as the VLPs from human papilloma virus, influenza virus, hepatitis B virus and human immunodeficiency virus-1 [28-31]. However, the secretion of IFN- $\gamma$ decreased as the VLPs dose increased, and even no significant difference was found between $50 \mu \mathrm{g}$ VLPs and PBS groups. This trend was consistent with a previous study [32] and requires further experiments to understand the details.

In summary, the CPV VP2 protein co-expressed with Tf16 in E.coli could assemble into VLPs similar with natural CPV virions in size and shape. The VLPs could stimulate strong immune responses in guinea pigs against CPV. Thus, the Tf16 co-expression system provides a new approach for producing CPV VLPs with high yield and efficiency. With the following improvements, a CPV VLP-based vaccine may be developed successfully in the future.

\section{Abbreviations}

CPV: Canine parvovirus; VLPs: Virus-like particles; TF: Trigger factor; E.coli: Escherichia coli; TEM: Transmission electron microscopy; DLS: Dynamic light scattering; CPE: Cytopathic effect; IPMA: Immunoperoxidase monolayer assay; HI: Hemagglutination inhibition; HA: Hemagglutination; RBCs: Red blood cells; ANOVA: Analysis of variance; SUMO: Small ubiquitin-like modifier

\section{Acknowledgments}

We thank Zhe Jia of Henan Agricultural University Veterinary Teaching Hospital, China, for providing feces of infected puppy, and Dr. Xiaokang Lu, Henan University of Chinese Medicine, for his excellent technical assistance.

\section{Funding}

This work was funded by grants from the National Key Research and Development Program of China (2016YFD0500704) and 1125 Talent Recruitment Program of Zhengzhou.

\section{Availability of data and materials}

All relevant information is provided in this current manuscript.

\section{Authors' contributions}

GZ, LN, PJ and YL contributed to the study conception and design. LN wrote the manuscript. HF and CC checked and revised it. JW and DL carried out the sequencing of CPV. PJ, YC, YW, YL helped with the animal experiments and contributed to the data analysis. All authors read and approved the final manuscript.

\section{Ethics approval and consent to participate}

All animal experiments were approved by Animal Experiment Committee of Henan Academy of Agricultural Sciences with the approval number (SYXK 2014-0007). The protocols were performed in accordance with the guidelines for the Welfare and Ethics of Laboratory Animals of China.

Consent for publication

Not applicable.

\section{Competing interests}

The authors declare that they have no competing interests.

\section{Publisher's Note}

Springer Nature remains neutral with regard to jurisdictional claims in published maps and institutional affiliations.

\section{Author details}

${ }^{1}$ College of Veterinary Medicine, Northwest A\&F University, Yangling 712100, China. ${ }^{2}$ Henan Provincial Key Laboratory of Animal Immunology, Henan Academy of Agricultural Sciences, Zhengzhou 450002, China. ${ }^{3}$ College of Animal Science and Veterinary Medicine, Henan Agricultural University, Zhengzhou 450002, China. ${ }^{4}$ Henan Zhongze Biological Engineering Co., Ltd., Zhengzhou 450019, China. 
Received: 4 March 2018 Accepted: 6 June 2018

Published online: 19 June 2018

\section{References}

1. Hayes MA, Russel RG, Mueller RW, Lewis RJ. Myocarditis in young dogs associated with a parvovirus-like agent. Can Vet J. 1979;20:126.

2. Goddard A, Leisewitz AL. Canine parvovirus. The veterinary clinics of North America small animal. Practice. 2010;40:1041-53.

3. Carmichael LE, Joubert JC, Pollock RV. Hemagglutination by canine parvovirus: serologic studies and diagnostic applications. Am J Vet Res. 1980;41:784-91.

4. Yuan W, Parrish CR. Canine parvovirus capsid assembly and differences in mammalian and insect cells. Virology. 2001:279:546-57.

5. Parrish CR, Have P, Foreyt WJ, Evermann JF, Senda M, Carmichael LE. The global spread and replacement of canine parvovirus strains. J Gen Virol. 1988;69(Pt 5):1111-6.

6. Parrish CR, Aquadro CF, Strassheim ML, Evermann JF, Sgro JY, Mohammed HO. Rapid antigenic-type replacement and DNA sequence evolution of canine parvovirus. J Virol. 1991;65:6544-52.

7. Buonavoglia C, Martella V, Pratelli A, Tempesta M, Cavalli A, Buonavoglia D, et al. Evidence for evolution of canine parvovirus type 2 in Italy. J Gen Virol. 2001;82:3021-5.

8. Zhou P, Zeng W, Zhang X, Li S. The genetic evolution of canine parvovirus a new perspective. PLoS One. 2017;12:e0175035.

9. Vaccination Guidelines G, Day MJ, Horzinek MC, Schultz RD. WSAVA guidelines for the vaccination of dogs and cats. J Small Anim Pract. 2010;51:1-32.

10. Dennis SJ, Meyers AE, Guthrie AJ, Hitzeroth II, Rybicki EP. Immunogenicity of plant-produced African horse sickness virus-like particles: implications for a novel vaccine. Plant Biotechnol J. 2017;16:442-50.

11. Qi T, Cui S. Expression of porcine parvovirus VP2 gene requires codon optimized E. Coli cells. Virus Genes. 2009;39:217-22.

12. Nishihara K, Kanemori M, Kitagawa M, Yanagi H, Yura T. Chaperone coexpression plasmids: differential and synergistic roles of DnaK-DnaJ-GrpE and GroEL-GroES in assisting folding of an allergen of Japanese cedar pollen, Cryj2, in Escherichia coli. Appl Environ Microbiol. 1998;64:1694-9.

13. Bhandari V, Houry WA. Substrate interaction networks of the Escherichia coli chaperones: trigger factor, DnaK and GroEL. Adv Exp Med Biol. 2015;883:271-94.

14. Liu CP, Zhou JM. Trigger factor-assisted folding of bovine carbonic anhydrase II. Biochem Biophys Res Commun. 2004;313:509-15.

15. Wang J, Lin $P$, Zhao H, Cheng $Y$, Jiang Z, Zhu H, et al. Continuing evolution of canine parvovirus in China: isolation of novel variants with an Ala5Gly mutation in the VP2 protein. Infect Genet Evol. 2016;38:73-8.

16. Lee DH, Bae SW, Park JK, Kwon JH, Yuk SS, Song JM, et al. Virus-like particle vaccine protects against H3N2 canine influenza virus in dog. Vaccine. 2013; 31:3268-73.

17. Xu J, Guo HC, Wei YQ, Dong H, Han SC, Ao D, et al. Self-assembly of viruslike particles of canine parvovirus capsid protein expressed from Escherichia coli and application as virus-like particle vaccine. Appl Microbiol Biotechnol. 2014;98:3529-38.

18. Park JS, Choi BK, Vijayachandran LS, Ayyappan V, Chong CK, Lee KS, et al. Immunodetection of canine parvovirus (CPV) in clinical samples by polyclonal antisera against CPV-VP2 protein expressed in Esherichia coli as an antigen. J Virol Methods. 2007;146:281-7.

19. Zeng F, Yeung W, Lu Y, Lun Z, Lv J, Liu F, et al. Expression, purification, and characterization of VP2 capsid protein of canine parvovirus in Escherichia coli. World J Microbiol Biotechnol. 2007;24:457-63.

20. Wong P, Houry WA. Chaperone networks in bacteria: analysis of protein homeostasis in minimal cells. J Struct Biol. 2004;146:79-89.

21. Hartl FU, Hayer-Hartl M. Molecular chaperones in the cytosol: from nascent chain to folded protein. Science. 2002;295:1852-8.

22. Mach $\mathrm{H}$, Volkin DB, Troutman RD, Wang B, Luo Z, Jansen $\mathrm{KU}$, et al. Disassembly and reassembly of yeast-derived recombinant human papillomavirus virus-like particles (HPV VLPS). J Pharm Sci. 2006;95:2195-206.

23. Lin S-Y, Chung Y-C, Chiu H-Y, Chi W-K, Chiang B-L, Hu Y-C. Evaluation of the stability of enterovirus 71 virus-like particle. J Biosci Bioeng. 2014;117:366-71.

24. Sanchez-Rodriguez SP, Munch-Anguiano L, Echeverria O, Vazquez-Nin G, Mora-Pale M, Dordick JS, et al. Human parvovirus B19 virus-like particles: in vitro assembly and stability. Biochimie. 2012;94:870-8.

25. Dominy BN, Perl D, Schmid FX, Brooks CL 3rd. The effects of ionic strength on protein stability: the cold shock protein family. J Mol Biol. 2002;319:541-54.
26. Feng $H, H u G Q$, Wang $H L$, Liang $M$, Liang $H$, Guo $H$, et al. Canine parvovirus VP2 protein expressed in silkworm pupae self-assembles into virus-like particles with high immunogenicity. PLoS One. 2014;9:e79575.

27. Dhur A, Galan P, Preziosi P, Hercberg S. Lymphocyte subpopulations in the thymus, lymph nodes and spleen of iron-deficient and rehabilitated mice. J Nutr. 1991;121:1418-24.

28. Garcia-Pineres A, Hildesheim A, Dodd L, Kemp TJ, Williams M, Harro C, et al. Cytokine and chemokine profiles following vaccination with human papillomavirus type 16 L1 virus-like particles. Clin Vaccine Immunol. 2007;14: 984-9.

29. Bright RA, Carter DM, Daniluk S, Toapanta FR, Ahmad A, Gavrilov V, et al. Influenza virus-like particles elicit broader immune responses than whole virion inactivated influenza virus or recombinant hemagglutinin. Vaccine. 2007;25:3871-8

30. Schirmbeck R, Bohm W, Reimann J. Virus-like particles induce MHC class Irestricted T-cell responses. Lessons learned from the hepatitis B small surface antigen. Intervirology. 1996;39:111-9.

31. Tsunetsugu-Yokota Y, Morikawa Y, Isogai M, Kawana-Tachikawa A, Odawara T, Nakamura T, et al. Yeast-derived human immunodeficiency virus type 1 p55(gag) virus-like particles activate dendritic cells (DCs) and induce perforin expression in gag-specific CD8(+) T cells by cross-presentation of DCs. J Virol. 2003:77:10250-9.

32. Ji P, Liu Y, Chen Y, Wang A, Jiang D, Zhao B, et al. Porcine parvovirus capsid protein expressed in Escherichia coli self-assembles into virus-like particles with high immunogenicity in mice and Guinea pigs. Antivir Res. 2017;139: $146-52$

Ready to submit your research? Choose BMC and benefit from

- fast, convenient online submission

- thorough peer review by experienced researchers in your field

- rapid publication on acceptance

- support for research data, including large and complex data types

- gold Open Access which fosters wider collaboration and increased citations

- maximum visibility for your research: over $100 \mathrm{M}$ website views per year

At BMC, research is always in progress.

Learn more biomedcentral.com/submissions 